\title{
Tsafon
}

Revue d'études juives du Nord

$81 \mid 2021$

Des synagogues à travers les âges Lieux de prières, lieux d'études et autres fonctions

\section{Keller-Rosenberg Lili, Et nous sommes revenus seuls}

\section{Danielle Delmaire}

\section{(2) OpenEdition \\ 1 Journals}

\section{Édition électronique}

URL : https://journals.openedition.org/tsafon/4014

DOI : $10.4000 /$ tsafon.4014

ISSN : 2609-6420

Éditeur

Association Jean-Marie Delmaire

\section{Édition imprimée}

Date de publication : 1 juillet 2021

Pagination : 160-161

ISSN : $1149-6630$

\section{Référence électronique}

Danielle Delmaire, «Keller-Rosenberg Lili, Et nous sommes revenus seuls », Tsafon [En ligne], 81 | 2021, mis en ligne le 01 juillet 2021, consulté le 16 septembre 2021. URL : http://journals.openedition.org/ tsafon/4014; DOI : https://doi.org/10.4000/tsafon.4014

Ce document a été généré automatiquement le 16 septembre 2021.

Tsafon. Revues d'études juives du Nord 


\title{
Keller-Rosenberg Lili, Et nous sommes revenus seuls
}

\author{
Danielle Delmaire
}

\section{RÉFÉRENCE}

Keller-Rosenberg Lili, Et nous sommes revenus seuls, Paris, Plon, avril 2021, 157 p., $15 €$.

Plus connue sous son nom d'épouse, Lili Leignel signe, chez Plon et avec la participation de Virginie Carton, son second livre sur sa déportation à Ravensbrück puis BergenBelsen, avec sa maman et ses deux frères : les enfants avaient respectivement onze ans, dix ans et trois ans au moment de leur arrestation, en octobre 1943, à Roubaix dans le Nord. Comme pour son livre précédent, elle adopte prioritairement le nom de sa maman, Charlotte Keller, épouse Rosenberg. Bel hommage rendu à cette mère de famille qui lutta avec une force et un courage exceptionnels pour que vivent, survivent ses trois jeunes enfants dans un univers concentrationnaire inhumain.

2 Inlassablement, Lili Leignel accomplit la "mission » qu'elle s'est donnée, dès lors qu'elle apprit que l'on était capable de nier la réalité de la Shoah : témoigner auprès des enfants et des adolescents de ce qu'elle et ses frères ont subi comme souffrances physiques et morales parce qu'ils étaient juifs. Elle a commencé à se rendre dans les écoles, collèges et lycées au début des années 1980, dans sa ville de Lille d'abord, dans la région du Nord ensuite et finalement partout en France et même en Allemagne. Tsafon a pu recueillir un premier récit et l'a publié dans son $\mathrm{n}^{\circ}$ 9-10 de l'été-automne 1992, p. 28-37. Plus récemment, des enseignants du collège Prévert à Houdain (Pas-de-Calais) ont à leur tour publié, fin 2017, ses souvenirs augmentés des lettres d'élèves reçues, en grand nombre, par Lili Leignel après ses passages dans leurs établissements.

Pour les éditions Plon, elle s'en tient au seul récit de sa déportation. Mais l'approche n'est plus la même. Alors qu'auparavant, elle mettait en avant les difficultés physiques, le titre du précédent ouvrage en témoigne: Moi, Lili Keller-Rosenberg, je suis encore là, rescapée de la Shoah et passeur de mémoire, ici, avec la présentation de ce qu'elle appelle sa 
«mission", elle s'arrête davantage sur les souffrances morales : Et nous sommes revenus seuls!, "revenus seuls» des camps abominables sans la maman, trop malade pour quitter Bergen-Belsen à l'ouverture de ce camp. Les enfants débarquent «seuls " à l'hôtel Lutétia, ignorant tout du sort du papa qui n'a pas survécu à Buchenwald.

Le récit débute donc par la fin, avec l'évacuation de Bergen-Belsen et la séparation douloureuse d'avec la maman inconsciente car atteinte de la phase la plus grave du typhus. "Nous restons seuls, désemparés. Livrés à nous-même» (p. 15) et plus loin "Nous sommes les seuls enfants de ce convoi de retour» (p. 17). Lors d'une étape à Bruxelles : «Et nous sommes là, tous les trois collés comme un seul bloc, étourdis dans cette foule inconnue » venue les accueillir (p. 19) ; «[...] mais personne n'est là pour nous. Personne n'est venu nous chercher » (p. 20). Ce n'est qu'après ces premières pages du retour traumatisant et peu libérateur que Lili Leignel reprend son récit de la vie familiale heureuse avant la guerre, l'arrestation en octobre 1943, de toute la famille, l'internement à la prison de Loos, près de Lille, puis à Saint-Gilles (Bruxelles), le séjour humiliant et dépravant à la caserne Dossin de Malines d'où partaient les convois de Juifs et de Tsiganes de Belgique et du nord de la France, vers Auschwitz.

5 C'est alors la séparation d'avec le père qui est dirigé, comme tous les hommes, vers Buchenwald tandis que les femmes et les enfants prennent la direction de Ravensbrück où la maman et les trois enfants côtoient des résistantes au caractère trempé (Geneviève de Gaulle, Martha Desrumaux entre autres), qui leur accordent une grande attention et aident la maman dans ses efforts à maintenir ses enfants en vie. BergenBelsen est également décrit dans toute son horreur: abondance des épidémies, monceaux de cadavres, la faim, la peur et la maman gravement malade, agonisante.

Dans les quarante dernières pages, Lili Leignel revient sur la solitude du retour puis le retour à la vie familiale avec la maman rentrée presque guérie mais sans le papa. Elle termine en persistant à évoquer sa "mission » : témoigner. "Et quand je regarde le chemin parcouru, les dizaines de milliers de jeunes croisés sur ma route avec lesquels j'ai pu échanger, auxquels j'ai pu transmettre mon témoignage, mon histoire, ma leçon de citoyenneté, de tolérance et d'humanisme, je crois que je peux commencer à affirmer: 'mission accomplie'» sont ses derniers mots. Car Lili Leignel refuse une évocation victimaire et larmoyante de son passé : de ce récit il faut tirer des leçons dont tiendront compte les adultes de demain. 